\title{
Narcotic reversal in hypercapnic dogs: comparison of nalox- one and nalbuphine
}

Reversal of opioid effects by naloxone (NX) can lead to significant cardiovascular problems. We have reported previously that hypercapnic dogs develop greater increases in blood pressure and plasma catecholamine (CA) levels than hypocapnic ones when reversed with naloxone. We have also demonstrated differences between NX and nalbuphine (NBPH) in producing excitatory adrenergic responses when administered during normocapnia. The present study was designed to investigate possible dissimilarities in cardiovascular and sympathetic events after administration of either NX or NBPH in dogs made hypercapnic following fentanyl administration. After induction of anaesthesia with thiopentone and intubation, two groups of dogs were maintained with controlled ventilation on enflurane in oxygen anaesthesia and given $50 \mu \mathrm{g} \cdot \mathrm{kg}^{-1}$ fentanyl $I V$. This caused a significant decrease in heart rate $(H R)(P<$ $0.001)$, mean arterial blood pressure $(M A P)(P<0.001)$, and plasma concentrations of norepinephrine $(N E)(P<0.002)$. Then, ventilation was decreased to produce a $\mathrm{PaCO}_{2}$ of 60 mmHg; this was accompanied by a significant elevation in plasma level of both epinephrine $(E P I)(P<0.02)$ and $N E$ $(P<0.001)$. Administration of $20 \mu \mathrm{g} \cdot \mathrm{kg}^{-1} \mathrm{NX}$ to six dogs resulted in immediate increases in $H R(P<0.01)$ and $M A P(P$ $<0.01$ ), and a further rise in $C A$ levels to greater than pre-fentanyl baseline values. In six other dogs, NBPH 10.3 $\left.\mathrm{mg} \cdot \mathrm{kg}^{-1}\right)$ caused increases in $H R(P<0.001)$ and $M A P(P<$ $0.001)$ only, and the MAP rise was significantly less than that seen in the $N X$ group $(P<0.01)$. Neither $N E$ nor EPI levels increased after NBPH. Absolute levels of EPI one minute after reversal with $N B P H$ were not greater than baseline and were

\section{Key words}

ANALGESICS: fentanyl;

ANTAGONISTS, NARCOTIC: nalbuphine, naloxone; CARBON DIOXIDE: hypercarbia.

From the Department of Anesthesiology, University of Califronia, Los Angeles, Center for the Health Sciences, Los Angeles, California, 90024-1778.

Address correspondence: Joan W. Flacke, Department of anesthesiology, BH-961, C.H.S., UCLA School of Medicine, Los Angeles, California, 90024-1778.
Christopher A. Mills MD, Joan W. Flacke MD, Werner E. Flacke MD, Byron C. Bloor MD, Marvin D. Liu MD significantly less than after NX $(P<0.05)$. Addition of NX after $N B P H$ caused a further significant increase in EPI to levels greater than baseline $(P<0.002)$. This study suggests that the abrupt, significant, and sustained increases in MAP and plasma levels of $C A$ which accompany narcotic reversal with $N X$ during hypercapnia are blunted if nalbuphine rather than naloxone is used.

$L$ 'antagonisme des effets des opiacés par le naloxone (NX) peut amener des problèmes cardiovasculaires significatifs. On a rapporté dans le passé que des chiens hypercapniques développaient une plus grande augmentation de la pression artérielle et des catécholamines plasmatiques (CA) que ceux qui sont hypocapniques lors de l'antagonisme avec le naloxone. On a aussi démontré des différences entre le naloxone et la nalbuphine (NBPH) dans la production de réponses adrénergiques lorsqu'administrés en normocapnie. Cette étude a été conçue afin d'investiguer les différences possibles dans les réponses sympathiques et cardiovasculaires après administration de soit NX ou NBPH chez des chiens rendus hypercapniques après administration de fentanyl. Après l'induction de l'anesthésie avec du thiopentone et intubation, deux groupes de chiens on été maintenus avec une ventilation contrôlée sous enflurane et oxygène et ont reçu $50 \mu \mathrm{g} \cdot \mathrm{kg}^{-1}$ de fentanl par voie intraveineuse. Ceci amena une diminution significative de la fréquence cardiaque $(H R)(P<0,001)$, pression artérielle moyenne (MAP) $(P<0,001)$, et des concentrations plasmatiques de norépinéphrine $(N E)(P<0,002)$. Par la suite, la ventilation ful diminuée afin de produire une $\mathrm{PaCO}_{2}$ de $60 \mathrm{mmHg}$; ceci fut accompagné par une augmentation significative des niveaux plasmatiques d'épinéphrine $(E P I)(P<0,02)$ et de norépinéphrine $(P<0,001)$. L'administration de $20 \mu \mathrm{g} \cdot \mathrm{kg}^{-1}$ de NXa six chiens a occasionné une augmentation immédiate de la fréquence cardiaque $H R(P<0,01)$ et de la $M A P(P<0,01)$, et une augmentation de la $C A$ d̀ un niveau supérieur aux valeurs de contrôle avant-fentanyl. Chez les six autres chiens, du NBPH $\left(0,3 \mathrm{mg} \cdot \mathrm{kg}^{-1}\right)$ a occasionné une augmentation de HR et de la MAP $(P<0,001)$ uniquement, et l'augmentation de la MAP était significativement moindre que celle observée dans le groupe $N X(P<0,01)$. Ni les niveaux de $N E$ ou EPI augmentèrent après le NBPH. Les niveaux absolus de EPI une minute après antagonisme avec le NBPH ne furent pas supe. 
rieurs à ceux de la valeur de contrôle et étaient significativement moindres qu'aprés NX $(P<0,005)$. L'addition de NX après NBPH a occasionné une augmentation significative des niveaux de EPI supérieurs à celui du contrôle $(P<0,002)$. Cette étude suggère qu'une augmentation brusque, significative, et soutenue de la MAP et des niveaux plasmatiques de CA qui accompagnent l'antagonisme des narcotiques avec le NX durant l'hypercapnie sont amoindris si le nalbuphine plutôt que le naloxone est utilisé

Nalbuphine, a narcotic of the agonist/antagonist type, ${ }^{1-4}$ has been reported to antagonize effectively postoperative respiratory depression caused by intraoperative narcotics, while retaining satisfactory analgesia. ${ }^{5-8} \mathrm{~A}$ recent study by Zsigmond et al. ${ }^{9}$ reported that antagonism of fentanylinduced respiratory depression with nalbuphine occurred without the adverse circulatory or endocrine changes that have been seen after naloxone. ${ }^{10-20}$ However, in some patients, hypertension, tachycardia, dysrhythmias, pulmonary oedema, and pain have been reported also after narcotics reversal with nalbuphine. ${ }^{21-25}$

Studies from our laboratory have shown that nalbuphine reversal of fentanyl in anaesthetized dogs produced cardiovascular changes similar to those seen after reversal with naloxone. ${ }^{1,14}$ In experiments in normocapnic animals, unlike the situation with naloxone, haemodynamic events after nalbuphine were not accompanied by rises in plasma catecholamine levels, yet plasma levels of both EPI and NE did rise significantly after the subsequent administration of naloxone. In other experiments, we have examined the heamodynamic and adrenergic events after naloxone in dogs with varying arterial carbon dioxide tensions. ${ }^{26}$ In that investigation, dogs which were hypercapnic at the time of naloxone administration responded with more rapid and greater increases in blood pressure and plasma catecholamine concentrations than did dogs which were hypocapnic. Anaesthetized and postanaesthetic patients are likely to have increased arterial carbon dioxide concentrations (from hypoventilation), at the time of narcotic reversal. Therefore, in light of (1) the demonstrated lesser effects of nalbuphine than naloxone in producing sympathetic stimulation during the normocapnic state, and (2) the exaggeration of the heamodynamic and adrenergic effects of naloxone during hypercapnia, the present investigation was designed to compare the actions of these two antagonists in the presence of an increased arterial $\mathrm{CO}_{2}$ tension. In other words, do the advantages offered by nalbuphine over naloxone under normocapnic conditions also occur in the hypercapnic state?

\section{Methods}

Two series of six dogs each were studied. All dogs (average weight $=15 \pm 1 \mathrm{~kg}$ ) were anaesthetized with 10 $\mathrm{mg} \cdot \mathrm{kg}^{-1}$ thiopentone, then given $20 \mathrm{mg}$ succinylcholine, and the tracheas were intubated following $2 \mathrm{mg} \cdot \mathrm{kg}^{-1}$ of four per cent lidocaine intratracheally. Controlled ventilation was with 1.5 per cent enflurane in oxygen, and tidal volume and rate were adjusted to achieve an arterial carbon dioxide tension of $35 \mathrm{mmHg}$.

After induction of anaesthesia, 20-gauge catheters were introduced percutaneously into a femoral artery for transduced blood pressure measurement and blood sampling, and into a femoral vein for injection of drugs and administration of intravenous fluids: five per cent dextrose in lactated Ringer's solution at a rate of five $\mathrm{ml} \cdot \mathrm{kg}^{-1} \cdot \mathrm{hr}^{-1}$. Electrocardiogram electrodes were attached, and blood pressure and heart rate were measured and recorded continuously (Hewlett-Packard Series 7758 polygraph). Arterial blood samples were taken at intervals for determination of blood gas tensions (Instrumentation Laboratories, Model Micro 13) and for measurement of plasma levels of norepinephrine and epinephrine by high performance liquid chromatography. ${ }^{27}$ Inspired enflurane and end-tidal carbon dioxide concentrations were measured continuously by mass spectrometry (Perkin Elmer, Model MGA 1 100). Oesophageal temperature was maintained at $38 \pm 0.5^{\circ} \mathrm{C}$.

For both groups of dogs, after control data were taken, fentanyl $50 \mu \mathrm{g} \cdot \mathrm{kg}^{-1}$ was infused over five minutes, and measurements were made five and $\mathbf{4 5}$ minutes later, all during normocapnia $\left(\mathrm{PaCO}_{2}=35 \mathrm{mmHg}\right)$. Respiratory rate and tidal volume were then decreased until the arterial carbon dioxide tension was $60 \mathrm{mmHg}$, and measurements were repeated after cardiovascular stability had been attained. None of the nonparalyzed dogs moved or attempted to breathe while hypercapnic. Next, vecuronium $0.1 \mathrm{mg} \cdot \mathrm{kg}^{-1}$ was given, followed in two minutes by the appropriate narcotic reversal agent: one group was given naloxone $20 \mu \mathrm{g} \cdot \mathrm{kg}^{-1}$, and the other group was given nalbuphine $0.3 \mathrm{mg} \cdot \mathrm{kg}^{-1}$. Measurements in both groups were repeated at one, five, and ten minutes thereafter. Dogs which had received nalbuphine were then given $20 \mu \mathrm{g} \cdot \mathrm{kg}^{-1}$ naloxone, and measurements were repeated one minute later.

All drugs used were commercial preparations: thiopentone sodium (Pentothal, Abbott Laboratories, IL); succinylcholine chloride (Anectine, Burroughs-Welcome, NC); lidocaine (Topical Xylocaine, Astra Pharmaceutical Products, MA); fentanyl citrate (Sublimaze, Janssen Pharmaceutica, $\mathrm{NJ}$ ); vecuronium bromide (Norcuron, Organon, NJ); naloxone hydrochloride (Narcan), and nalbuphine (Nubain, DuPont Pharmaceuticals, Puerto Rico).

Intragroup changes were examined by means of analysis of variance for repeated measure, followed by Bonferroni's $\mathrm{t}$ test. Wilcoxon signed rank test was used where 


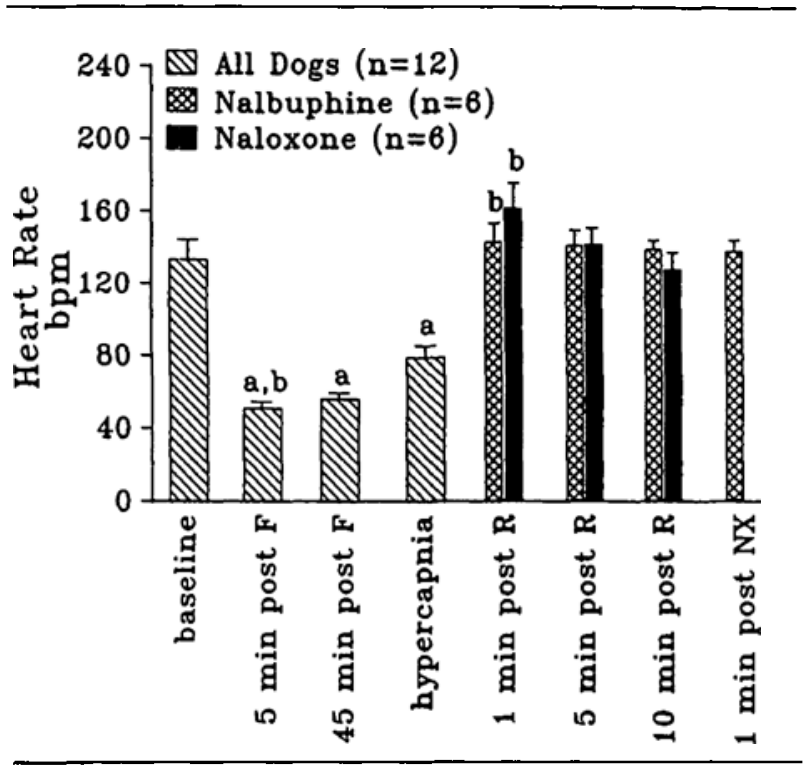

FIGURE 1 Mean ( \pm SEM) heart rates of the two groups of dogs at the times indicated. Data from all animals have been pooled for the four observation points before narcotic reversal with either nalbuphine (cross-hatched bars) or naloxone (solid bars) Post $-\mathrm{F}=$ after fentanyl infusion; post $-\mathrm{R}=$ after reversal agent given; post-NX = after naloxone administration (in the nalbuphine group only). Statistically significant differences $(P<0.05)$ are indicaled as $a=$ different from (paired) baseline values; $b=$ different from preceding values; $c=$ intergroup difference; $d=$ different from values at one minute after nalbuphine.

indicated. Unpaired $t$ tests were used for intergroup comparisons. $P<0.05$ was considered to be statistically significant.

\section{Results}

All results are reported as mean values \pm SEM. As the protocol was identical for the two groups of dogs until the administration of the reversal agent, and no intergroup differences were present, data from all 12 dogs have been pooled for the first four measurement points (Figures 1 to 4). Measurements after reversal are treated separately for the naloxone and nalbuphine groups, and are compared with their own paired values in the determination of intragroup changes.

The administration of fentanyl produced significant and sustained decreases in heart rate $(P<0.001)$ (Figure $1)$, mean arterial blood pressure $(P<0.001)$ (Figure 2$)$, and plasma norepinephrine levels $(P<0.002)$ (Figures 3 and 4), as has been reported previously. ${ }^{13,25}$ After hypercapnia was produced, the plasma epinephrine and norepinephrine levels rose significantly $(P<0.02$ and $P$ $<0.001$ respectively), but heart rate and blood pressure did not change. From the baseline measurements through

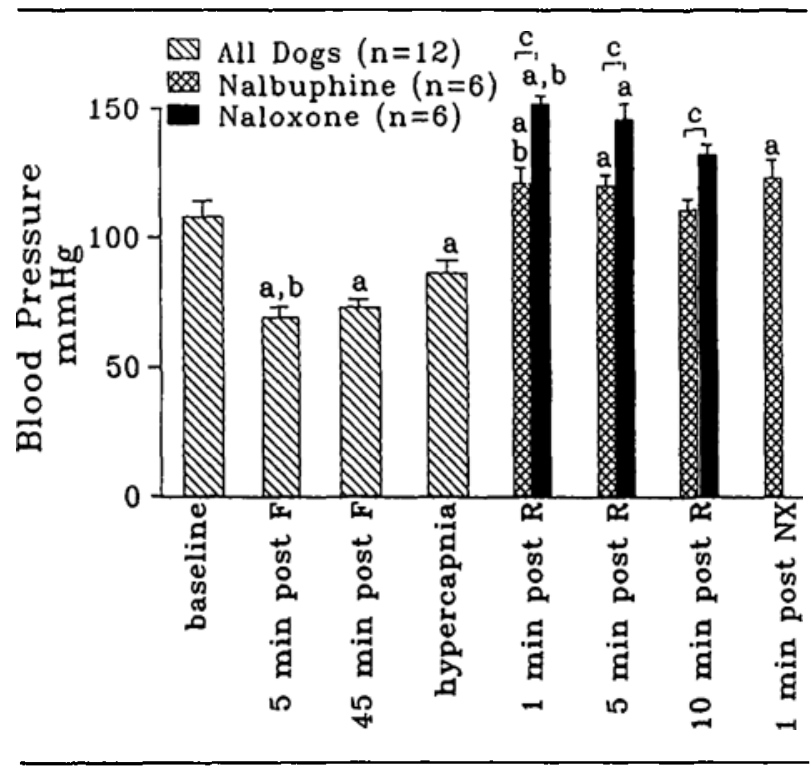

FIGURE 2 Mean values ( \pm SEM) of mean anerial pressure in the two groups of dogs. See caption to Figure I for explanation.

the hypercapnic measurements, there were no differences between the two groups in any of the functions measured.

The rapid administration of $20 \mu \mathrm{g} \cdot \mathrm{kg}^{-1}$ of naloxone caused an immediate, significant, and sustained (through the ten-minute measurement period) increase in heart rate $(P<0.01)$ back to baseline levels. In addition, mean arterial blood pressure $(P<0.01)$ and plasma EPI $(P<$ 0.05 ) were increased to levels significantly greater than baseline one minute after naloxone administration; these increases were sustained for at least five minutes (in the case of mean blood pressure) or ten minutes (in the case of EPI). Mean NE levels also increased to greater than baseline levels, but because of the large standard error these were not significantly elevated over the prenaloxone levels. (NE values increased in five of the six dogs $(P=0.062$ by Wilcoxon signed rank test); the large standard error in the value one minute after naloxone was caused by an extremely large increase in one dog to a level of nearly $1700 \mathrm{pg} \cdot \mathrm{ml}^{-1}$.)

In the other group of dogs, which received $0.3 \mathrm{mg} \cdot \mathrm{kg}^{-1}$ nalbuphine, the rapid administration of this agent caused a similar significant increase in heart rate $(P<0.001)$ but significantly less increase in blood pressure than seen after naloxone. Moreover, plasma catecholamine levels did not increase significantly after nalbuphine. However, the subsequent administration of naloxone to dogs which had received nalbuphine caused a significant rise in plasma epinephrine levels to above baseline values. Plasma norepinephrine levels increased to above baseline also $(P<0.005)$. 


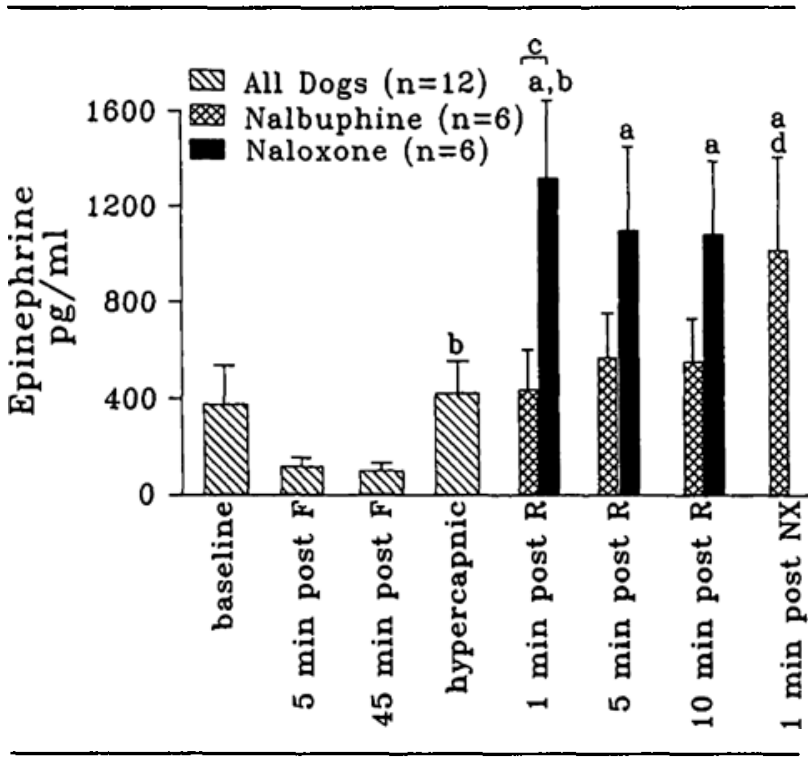

FIGURE 3 Plasma epinephrine levels. See caption to Figure 1 for explanation.

Although there were no significant intergroup differences in heart rate, blood pressures were significantly higher at all sampling times after reversal in dogs which received naloxone than in dogs which received nalbuphine $(P<0.002$ at $1 \mathrm{~min} ; P<0.01$ at $5 \mathrm{~min}$; and $P$ $<0.005$ at $10 \mathrm{~min}$ ).

One minute after reversal, plasma epinephrine levels were higher in dogs which had received naloxone than in dogs which had received nalbuphine $(P<0.05)$. Because of the large standard error in the naloxone group, mentioned above, intergroup differences in norepinephrine levels at one minute after reversal were not significant.

\section{Discussion}

Numerous examples of misadventure following the administration of the pure antagonist naloxone to patients who had previously been given narcotics have been cited in the literature. ${ }^{10-13,15-20}$ Blood gases at the time of reversal have usually not been reported. A previous study in our laboratory ${ }^{26}$ demonstrated the important role of hypercapnia in determining the magnitude of cardiovascular and sympathetic stimulation following narcotic reversal. Hypercapnic dogs developed significantly greater increases in blood pressure and plasma catecholamines after naloxone reversal of fentanyl than did hypocapnic or normocapnic dogs. ${ }^{26}$ Several investigators ${ }^{5-8.23}$ have reported that nalbuphine can be used clinically to provide at least partial antagonism of the respiratory depressant effects of narcotics without the sometimes calamitous

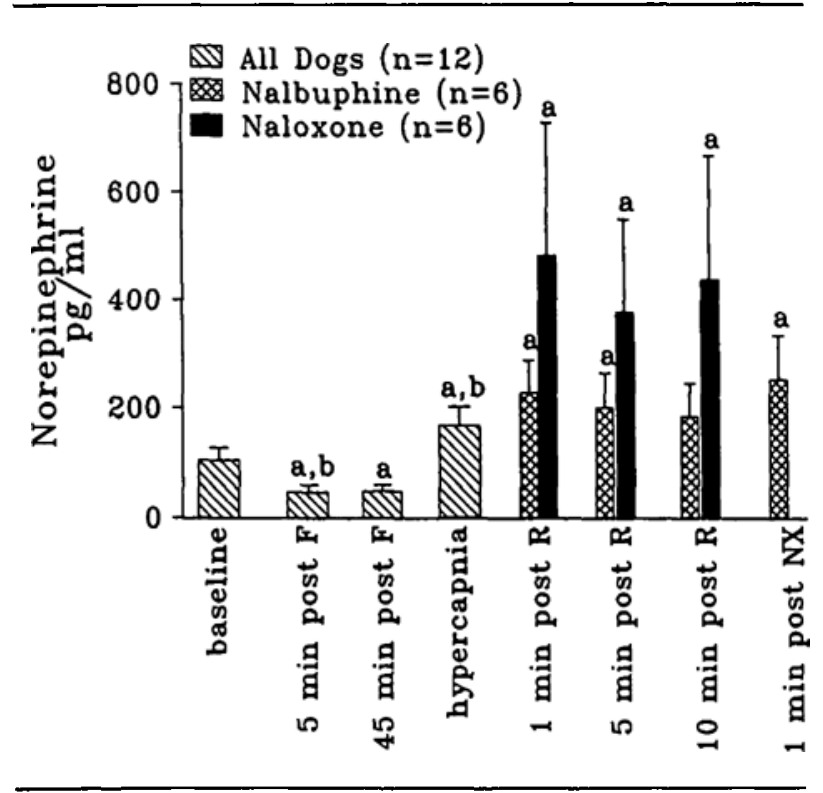

FIGURE 4 Plasma norepinephrine levels. See caption to Figure 2 for explanation.

cardiovascular events that may surround the use of naloxone in the same setting. However, other reports concerning nalbuphine have not been so favorable: ${ }^{21,22,24,25}$ tachycardia, dysrhythmias, hypertension, incisional pain and pulmonary oedema have been described following the administration of nalbuphine in doses averaging about $0.3 \mathrm{mg} \cdot \mathrm{kg}^{-1}$.

A transition from controlled ventilation to spontaneous ventilation usually takes place at the end of anaesthesia. However, in the presence of significantly elevated residual narcotic levels, the respiratory drive will be suppressed to a degree insufficient to support adequate spontaneous respiration, and reversal of this suppression with a narcotic antagonist or partial agonistantagonist may be contemplated. Ideally, the reversal agent would be specific for the respiratory-depressant, rather than for the pain-suppressive, effects of the narcotic. Certainly, a pure antagonist such as naloxone would restore the $\mathrm{CO}_{2}$ response curve and get the patient breathing again (in the absence of other adverse factors such as neuromuscular paralysis, hypothermia, mechanical obstruction, or volatile anaesthetic overdose), but possibly at the cost of extreme sympathetic stimulation. ${ }^{14}$

A modified $\mathrm{CO}_{2}$ response titration is often performed while attempting to get patients to breathe at the end of anaesthesia, thus balancing factors stimulating respiration (pain, hypercapnia, and perhaps hypoxia) against narcotic-induced respiratory depression. In the process of this titration, a "light hand on the bag" produces ever- 
increasing hypercapnia until the level is reached where the patient begins to breathe. Many operating rooms are equipped with some form of capnometer, and relatively precise measurements of end-tidal (and, presumably, arterial) carbon dioxide levels can be made. If the "threshold" for breathing is unacceptably high, narcotic reversal may be attempted to lower it. This investigation has delineated the haemodynamic and sympathetic sequelae of such reversal by either a pure antagonist, or a partial agonist/antagonist, during hypercapnia.

In these experiments, the administration of $50 \mu \mathrm{g} \cdot \mathrm{kg}^{-1}$ of fentanyl promptly and nearly completely abolished sympathetic outflow, lowering heart rate and blood pressure. This finding is in agreement with previous experience in our laboratory, ${ }^{14,26}$ which has proved that the hypotensive effects of fentanyl are entirely indirect, and that, even at higher doses than in the present experiments, fentanyl is devoid of direct cardiac depression. ${ }^{29}$ In the present protocol, ventilation was decreased to produce hypercapnia; this change abruptly and significantly increased plasma catecholamine concentrations, but blood pressure and heart rate were not significantly increased.

Care was taken in choosing the doses of narcotic reversal agents used in these experiments. That of naloxone, $0.4 \mathrm{mg}$ (or an average of about $30 \mu \mathrm{g} \cdot \mathrm{kg}^{-1}$ ), is certainly more than enough to reverse the effects of the fentanyl. The case reports citing misadventure following naloxone use report an average of about $0.4 \mathrm{mg}$ naloxone per patient (or about $5 \mu \mathrm{g} \cdot \mathrm{kg}^{-1}$ ). Naloxone itself, even in very high doses (nearly $6000 \mu \mathrm{g} \cdot \mathrm{kg}^{-1}$ ), has been reported to be without cardiovascular effect. ${ }^{28}$ In the case of nalbuphine, which has mixed agonist-antagonist effects, a compromise was reached: the "ceiling" dose, above which further increases in either analgesia, or antagonism, will not occur, has been reported ${ }^{1,30}$ as about 0.2 $\mathrm{mg} \cdot \mathrm{kg}^{-1}$. Unless extremely high (nonphysiological) doses of nalbuphine were used, no further narcotic reversal would likely accompany a dose higher than the $0.3 \mathrm{mg} \cdot \mathrm{kg}^{-1}$ which was selected.

After administration of naloxone, the sympathetic and cardiovascular stimulation was profound and sustained. The administration of nalbuphine also stimulated heart rate and blood pressure significantly. In addition to this autonomically mediated activation, $\mathrm{we}^{26}$ and others ${ }^{30}$ have demonstrated that, in the absence of autonomic tone, an elevated arterial carbon dioxide tension brings about direct depressant effects on the cardiovascular system: namely, bradycardia and vasodilatation. These opposing direct effects may preclude an even greater autonomically mediated (indirect) rise in heart rate and blood pressure. ${ }^{25}$ Two differences exist between the reversal by the pure agonist and the partial agonist/ antagonist: first, the increases in blood pressure were significantly greater at all times after reversal in the hypercapnic dogs given naloxone. Second, a significant increase in either epinephrine or norepinephrine levels was not found at any time after nalbuphine. Naloxone, on the other hand, did cause adrenergic excitation, whether administered alone or added after nalbuphine. This was true in both normocapnic ${ }^{1}$ and hypercapnic dogs (Figures 2 and 3 ). Thus, those factors which are apt to compromise cardiovascular function severely and dangerously are more pronounced after naloxone than after nalbuphine administration. Dangerous arrhythmias are known to occur more frequently in the presence of high sympathetic tone; and, of course, the resultant hypertension per se is not without potential sequelae such as aneurysm rupture, ${ }^{12}$ stroke, and cardiac ischaemia. Peripheral vasoconstriction can lead to fluid shifting from the systemic venous to the pulmonary circulation. ${ }^{13}$

These differences between naloxone and nalbuphine may be related to the ways in which each reacts with the different opiate receptors. Specifically, most opioids stimulate mu receptors to a large degree, and kappa receptors to a lesser degree. At the doses used in these experiments, nalbuphine antagonizes narcotic effects at the mu receptor, but at the same time stimulates the kappa receptors. ${ }^{3,4}$ Naloxone, on the other hand, antagonizes narcotic effects at all receptors, but has no agonist effects of its own. The "ceiling effect" for the agonist-antagonist agent nalbuphine (respiratory depression and analgesic effect) has been well described; ${ }^{31,32}$ it is presumed that the dose of narcotic used in these experiments was sufficient so that both the agonistic and the antagonistic effects of nalbuphine were present. ${ }^{1}$

In conclusion, fentanyl has been shown, once again, to diminish sympathetic outflow in dogs; however, the institution of hypercapnia did elicit some adrenergic response even in these narcotized, well-anaesthetized animals. A bolus dose of $20 \mu \mathrm{g} \cdot \mathrm{kg}^{-1}$ naloxone caused a further increase in plasma catecholamine levels and increased heart rate and blood pressure significantly. The administration of an equipotent dose of nalbuphine in the same model not only produced significantly less rise in blood pressure, but was unaccompanied by significantly increased sympathetic outflow. Thus, the previous finding that narcotic reversal during normocapnia may be "less stressful" with nalbuphine than with naloxone has now been extended to include the inherently more dangerous ${ }^{26}$ hypercapnic situation. It should be noted, however, that in these experiments the dose and rate of administration of the antagonists were selected to show maximal haemodynamic responses. It may be possible, of 
course, to attenuate both haemodynamic and hormonal effects of reversal by giving the naloxone slowly and with careful titration.

\section{References}

1 Flacke JW. Antagonism of opioid analgesics with nalbuphine and naloxone. Seminars in Anesthesia. Katz RL (Ed.). Orlando: Grune and Stratton Inc. 1988; 7: 178-91.

2 Fahmy NR. Agonist/antagonist opioid analgesics: nalbuphine hydrochloride. In: Opioids in Anesthesia. Estafanous FG (Ed.). Boston: Butterworth Publishers. 1984, 20-7.

3 Jaffe $J H$, Martin WR. Opioid analgesics and antagonists. In: The Pharmacological Basis of Therapeutics. Gilman AG, Goodman LS, Rall TY, Murad F (Eds.). New York: Macmillan Publishing Co. 1985, 491-527.

4 Hug CC. New narcotic analgesics and antagonists in anesthesia. Seminars in Anesthesia. Katz RL (Ed.). Orlando: Grune and Stratton, Inc. 1982; 1: 14-209.

5 Freye $E$, Azevedo $L$, Hartung $E$. Reversal of fentanyl related respiratory depression with nalbuphine. Effects on the $\mathrm{CO}_{2}$-response curve in man. Acta Anaesthesiol Belg 1985; 4: 365-74.

6 Latasch L, Probst S, Dudziak R. Reversal by nalbuphine of respiratory depression caused by fentanyl. Anesth Analg 1984; 63: 814-6.

7 Magruder MR, Delaney RD, DiFazio CA. Reversal of narcotic-induced respiratory depression with nalbuphine hydrochloride. Anesthesiol Reviews 1982; 9: 34-7.

8 Schaer $H$, Baasch $K$, Achtari $R$. Nalbuphin nach enfluran oder fentanyl - wirkungen auf kreislauf und atmung. Anaesthesist 1986; 35: 478-84.

9 Zsigmond EK, Durrani Z, Barabas E, Wang XY, Tran $L$. Endocrine and hemodynamic effects of antagonism of fentanyl-induced respiratory depression by nalbuphine. Anesth Analg 1987; 66: 421-16.

10 Andree $R A$. Sudden death following naloxone administration. Anesth Analg 1980; 59: 782-4.

11 Azar I, Turndorf $H$. Severe hypertension and multiple atrial premature contractions following naloxone administration. Anesth Analg 1979; 58: 524-5.

12 Estilo AE, Cottrell JE. Naloxone, hypertension, and ruptured cerebral aneurysm. Anesthesiology 1981; 54: 352.

13 Flacke JW, Flacke WE, Williams GD. Acute pulmonary edema following naloxone reversal of high-dose morphine anesthesia. Anesthesiology 1977; 47: 376-8.

14 Flacke JW, Flacke WE, Bloor BC, Olewine $S$. Effects of fentanyl, naloxone, and clonidine on hemodynamics and plasma catecholamine levels in dogs. Anesth Analg 1983; 62: 305-13.
15 Levin ER, Sharp B, Drayer JIM, Weber MA. Case report: severe hypertension induced by naloxone. Am J Med Sci 1985; 290: 70-2.

16 Michaelis $L L$, Hickey $P R$. Ventricular irritability associated with the use of naloxone hydrochloride. Ann Thorac Surg 1974; 18: 608-14.

17 Pariridge $B L$, Ward $C R$. Pulmonary edema following low-dose naloxone administration. Anesthesiology 1986; 65: 709-10.

18 Prough DS, Roy R, Bumgarner J, Shannon G. Acute pulmonary edema in healthy teenagers following conscrvative doses of intravenous naloxone. Anesthesiology 1984; 60: 485-6.

19 Taff $R H$. Pulmonary edcma following naloxone administration in a patient without heart disease. Anesthesiology $1983 ; 59: 576-7$.

20 Tanaka $G Y$. Hypertensive reaction to naloxone. JAMA 1974; 228: 25-6.

21 Blaise GA, McMichan JC, Nugent M, Hollier LH. Nalbuphine produces side-effects while reversing narcoticinduced respiratory depression. Ancsth Analg 1986; 65: S19.

22 DesMarteau JK, Cassot AI. Acute pulmonary edema resulting from nalbuphine reversal of fentanyl-induced respiratory depression. Anesthesiology 1986; 65: 237.

23 Moldenhauer CC, Roach GW, Finlayson DC et al. Nalbuphine antagonism of ventilatory depression following high-dose fentanyl anesthesia. Anesthesiology 1985; 62: 647-50.

24 Ramsay JG, Higgs BD, Wynands JE, Robbins $R$, Townsend $G E$. Early extubation after high-dose fentanyl anaesthesia for aortocoronary bypass surgery: reversal of respiratory depression with low-dose nalbuphine. Can Anaesth Soc J 1985; 32: 597-606.

25 Tabatabai $M$, Javadi $P$, Tadjziechy $M$, Mazloomdoost $M$. Effect of nalbuphine hydrochloride on fentanylinduced respiratory depression and analgesia. Anesthesiology 1984; 61: A475.

26 Mills CA, Flacke JW, Miller JD, Davis LJ, Bloor BC, Flacke WE. Cardiovascular effects of fentanyl reversal by naloxone at varying arterial carbon dioxide tensions in dogs. Anesth Analg 1988; 67: 730-6.

27 Watson $E$. Liquid chromatography with electrochemical detection for plasma norepinephrine and epinephrine. Life Sci 1981; 28: 493-7.

28 Freye $E$. Effects of high dosages of fentanyl, meperidine, and naloxone in dogs. Anesth Analg 1974; 53: 40-7.

29 Flacke JW, Davis $L$, Flacke WE, Bloor BC, Van Etten $A P$. Effects of fentanyl and diazepam in dogs deprived of autonomic tone. Anesth Analg 1985; 64: 1053-9. 
30 Morris ME, Millar RA. Blood pH/plasma catecholamine relationships: respiratory acidosis. Br J Anaesth 1962; 34: 672-81.

31 Gal TJ, DiFazio CA, Moscicki J. Analgesic and respiratory depressant activity of nalbuphine: a comparison with morphine. Anesthesiology 1982; 57: 367-74.

32 Romagnoli A, Keats AS. Ceiling effect for respiratory depression by nalbuphine. Clin Pharmacol Ther 1980; 27: 478-85. 